\title{
Stability of A Non-Homogenous Porous Plate by Using Generalized Differantial Quadrature Method
}

\author{
Şeref Doğuşcan AKBAŞ \\ Bursa Technical University, Department of Civil Engineering, Bursa, Turkey \\ E-mail address: serefda@yahoo.com \\ Received date: June 2017 \\ Accepted Date: July 2017
}

\begin{abstract}
This paper presents stability analysis of a non-homogeneous plate with porosity effect. Material properties of the plate vary in the thickness direction and depend on the porosity. In the solution of the problem, the Generalized Differential Quadrature method is used. In the porosity model, uniform porosity distribution is considered. The effects of the porosity and material distribution parameters on the critical buckling of the non-homogeneous plate are investigated.
\end{abstract}

Keywords: Non-Homogeneous Plate; Porosity; Generalized Differential Quadrature Method.

\section{Introduction}

Non-homogeneous structures, namely functionally graded structures are a type of composites where the volume fraction of the materials constituents vary gradually, giving a non-uniform microstructure with continuously graded macro properties such as elasticity modulus, density, heat conductivity, etc.. Typically, in non-homogeneous structures, one face of a structural component is ceramic that can resist severe thermal corrosion effects and the other face is metal which has excellent structural strength.

Non-homogeneous structures have been an area of intensive research over the last decade. Because of the wide material variations and applications, it is important to study the static and dynamic analysis of Non-homogeneous structures, such as plates. Therefore, an intensive study has been conducted recently on vibration of structures made of FGMs (i.e., [1-42]).

In the literature, some studies about the porosity effect in the Non-homogeneous structures are; Wattanasakulpong and Ungbhakorn [43] investigated vibration analysis of porous FG beams. Mechab et al. $[44,45]$ examined free vibration analysis of a FG nano-plate resting on elastic foundations with the porosities effect. Şimşek and Aydın [46] examined forced vibration of FG microplates with porosity effects based on the modified couple stress theory. Jahwari and Naguib [47] investigated FG viscoelastic porous plates with a higher order plate theory and statistical based model of cellular distribution. Vibration characteristics of FG beams with porosity effect and various thermal loadings are investigated by [48-49]. Linear/ nonlinear analysis of buckling and vibration of FG beams 
reinforced porous nanocomposite are investigated by Chen et al. [50] and Kitipornchai et al. [51]. Akbaş [52] investigated static and vibration of FG porous plates by using Navier solution.

Stability analysis of a simply supported non-homogeneous plate is investigated with porosity effect by using Generalized Differential Quadrature Method based on the classical plate theory. The effects of the porosity and material distribution parameters on the critical buckling loads of the nonhomogeneous plate are examined.

\section{Formulations}

A simply supported rectangular non-homogeneous porous plate with thickness $h$ in $X_{3}$ direction, the lengths of $L_{X}$ and $L_{Y}$ the in $X_{1}$ and $X_{2}$ directions, respectively as shown in Figure 1. The nonhomogeneous plate is subjected to biaxial plane compressive loads $N$ in both $X_{1}$ and $X_{2}$ directions, respectively.
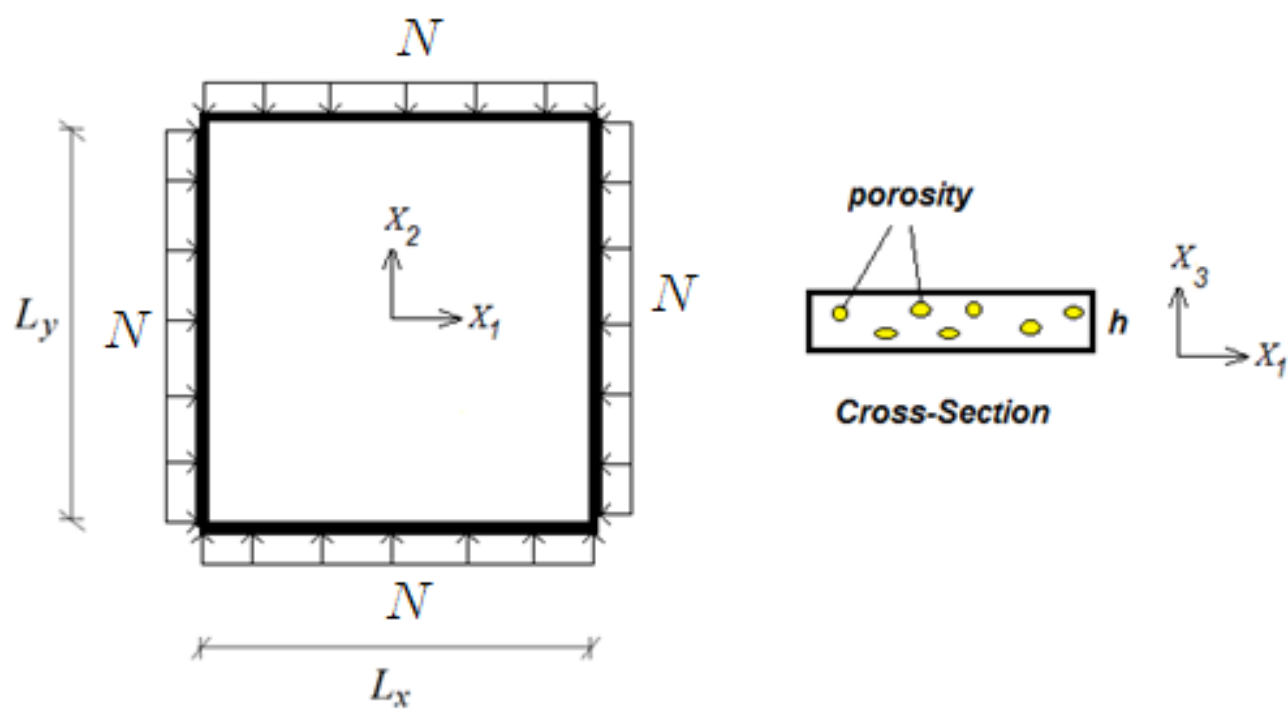

Fig. 1. A non-homogeneous plate subjected biaxial compressive loads with porosity.

The effective material properties of the non-homogeneous plate, $P$, such as, Young's modulus $E$, Poisson's ratio $v$, and shear modulus $G$ vary continuously in the thickness direction ( $X_{3}$ axis) according to a power-law function. In the porosity model, the porosity spread uniformly though height direction. According to the power law distribution, the effective material property with porosity can be expressed as follows:

$$
P\left(X_{3}\right)=\left(P_{T}-P_{B}\right)\left(\frac{X_{3}}{h}+\frac{1}{2}\right)^{k}+P_{B}-\left(P_{T}+P_{B}\right) \frac{a}{2}
$$

where $a(a<<1)$ is the volume fraction of porosities. When $a=0$, the plate becomes perfect nonhomogeneous plate.

According to classical plate theory, the strain- displacement relations are expressed as

$$
\varepsilon_{X_{1}}=\frac{\partial u}{\partial X_{1}}=\varepsilon_{X_{1}}{ }^{0}-X_{3} \frac{\partial^{2} \mathrm{v}}{\partial X_{1}{ }^{2}}
$$




$$
\begin{gathered}
\varepsilon_{X_{2}}=\frac{\partial v}{\partial X_{2}}=\varepsilon_{X_{2}}{ }^{0}-X_{3} \frac{\partial^{2} \mathrm{v}}{\partial X_{2}{ }^{2}} \\
\gamma_{X_{1} X_{2}}=\frac{1}{2}\left(\varepsilon_{X_{1} X_{2}}{ }^{0}-\frac{\partial^{2} \mathrm{v}}{\partial X_{1} \partial X_{2}}\right)
\end{gathered}
$$

where $u, v, w$ are $X_{1}, X_{2}$ and $X_{3}$ components of the displacements respectively. The constitutive equations of the non-homogeneous plate are as follows:

$$
\sigma_{\mathrm{ij}}\left(X_{3}, a\right)=\frac{E\left(X_{3}, a\right)}{\left(1-v^{2}\right)}\left[v \varepsilon_{k l} \delta_{i j}+(1-v) \varepsilon_{i j}\right]
$$

The stress resultants of the non-homogeneous plate are given as follows;

$$
N_{i j}=\int_{-0.5 h}^{0.5 h} \sigma_{\mathrm{ij}} d X_{3} i=j, M_{i j}=\int_{-0.5 h}^{0.5 h} \sigma_{\mathrm{ij}} X_{3} d X_{3}, Q_{i j}=\int_{-0.5 h}^{0.5 h} \sigma_{\mathrm{ij}} d X_{3} \quad i \neq j
$$

where $N_{i j}, M_{i j}$ and $Q_{i j}$ are normal force, moment and shear forces, respectively. The stability equation of the non-homogeneous plate is given as follows:

$$
\nabla^{4} v-\frac{A_{1}\left(1-v^{2}\right)}{A_{1} A_{3}-A_{2}^{2}}\left(N_{1}{ }^{0} \frac{\partial^{2} \mathrm{v}}{\partial X_{1}^{2}}+N_{2}{ }^{0} \frac{\partial^{2} \mathrm{v}}{\partial X_{2}^{2}}\right)=0
$$

where $N_{1}{ }^{0}$ and $N_{2}{ }^{0}$ are the pre-buckling force resultants, $A_{1}, A_{2}, A_{3}$ are expressed as follows:

$$
\left(A_{1}, A_{2}, A_{3}\right)=\int_{-0.5 h}^{0.5 h} E\left(X_{3}, a\right)\left(1, X_{3}, X_{3}^{2}\right) d X_{3}
$$

The boundary conditions at the simple supported plate ends are as follows;

$$
\begin{aligned}
& v\left(X_{1}, 0\right)=v\left(L_{X}, 0\right)=w\left(0, X_{2}\right)=w\left(0, L_{Y}\right)=0 \\
& M\left(X_{1}, 0\right)=M\left(L_{X}, X_{2}\right)=M\left(X_{1}, L_{Y}\right)=M\left(0, X_{2}\right)=0
\end{aligned}
$$

In the solution of the governing equations, the Generalized Differential Quadrature Method is used. In the differential quadrature method, the derivatives of a function are written as linear summation of the values at all points in the domain [53-56];

$$
\frac{d^{(p)} w\left(x_{j}\right)}{d x^{(p)}} \approx \sum_{i=1}^{n} B_{j i}^{(p)} w\left(x_{i}\right)
$$

$w$ here $n$ is the number of the points in the domain, $p$ is the order of derivative in the function, $B_{j i}^{(p)}$ is the weighting coefficient with $p$ th derivative of the function with respect to $x$. The weight coefficients for first-order derivative $(p=1)$ are as follows [53,54];

$$
B_{j i}^{(1)}=\left\{\begin{array}{c}
\frac{\prod_{j=1}^{n}\left(x_{j}-x_{i}\right)}{\left(x-x_{j}\right) \prod_{j=1}^{n}\left(x_{i}-x_{j}\right)} \\
-\sum_{j=1, i \neq j}^{n} B_{j i}^{(1)} \quad i=j
\end{array} \quad i \neq j\right.
$$

For the higher order derivatives, the weight coefficient is expressed as follows:

$$
B_{j i}^{(p)}=\sum_{r=1}^{n} B_{j r}^{(1)} B_{r i}^{(p-1)} \quad(i, j=1, n)
$$


For determined the sampling points in the domain, Chebyshev-Gauss-Lobatto grid points is employed[53,54];

$$
\begin{array}{ll}
x_{j}=\frac{1}{2}\left[1-\cos \left(\frac{j-1}{n-1} \pi\right)\right] & \left(j=1, n_{x 1}\right) \\
x_{i}=\frac{1}{2}\left[1-\cos \left(\frac{i-1}{n-1} \pi\right)\right] & \left(i=1, n_{x 2}\right)
\end{array}
$$

where $n_{x 1}$ and $n_{x 2}$ are the number of the grid points in $X_{1}$ and $X_{2}$ direction, respectively.

Substituting eqs. (8-11) into eq. (5), and then using Generalized Differential Quadrature discretization, the governing equations of the problem can be obtained as follows;

$$
\begin{aligned}
& \left(\sum_{k=1}^{n_{x 1}} B_{j k}^{(4)} v_{k j}+2 \sum_{k=1}^{n_{x 1}} \sum_{m=1}^{n_{x 2}} B_{j k}^{(2)} B_{i m}^{(2)} v_{k m}+\sum_{k=1}^{n_{x 2} B_{i k}^{(4)}} v_{k i}\right)- \\
& \frac{A_{1}\left(1-v^{2}\right)}{A_{1} A_{3}-A_{2}^{2}}\left(N_{1}{ }^{0} \sum_{k=1}^{n_{x 1}} B_{j k}^{(2)} v_{k j}+N_{2}{ }^{0} \sum_{k=1}^{n_{x 2}} B_{i k}^{(2)} v_{k i}\right)=0 \quad\left(j=1, n_{x l}\right),\left(i=1, n_{x 2}\right),(k=1, \mathrm{p}+1)
\end{aligned}
$$

The dimensionless critical buckling load can be expressed as follows;

$$
\bar{N}_{\mathrm{cr}}=N_{c r} \frac{L_{X}^{2}}{E_{B} h^{3}}
$$

\section{Numerical Results}

In the numerical results, the dimensionless critical buckling loads $\bar{N}_{\text {cr }}$ are presented in figures for different porosity parameters and material distributions. The rectangular non-homogeneous porous plate considered in numerical examples is made of Zirconia $(\mathrm{E}=151 G P a, v=0.3)$ and Steel $(\mathrm{E}=210 G P a$, $v=0.3)$. The top surface material of the non-homogeneous plate is Zirconia, the bottom surface material of the non-homogeneous plate is Steel. When $k=0$ and $k=\infty$, the material of the plate gets homogeneous Zirconia and homogeneous Steel, respectively, according to Eq. (1). The dimensions of the nonhomogeneous plate are considered as follows: $h=0.2 m, L_{X}=3 m, L_{Y}=3 m$ in the numerical examples. In the numerical calculations, the numbers of the grid points are taken as $n_{x l}=n_{x 2}=20$.

In figure 2, the effect of the material distribution parameter $k$ on the dimensionless critical buckling loads of the porous non-homogeneous plate is presented for $a=0$. As seen from figure 2 , the dimensionless critical buckling loads increase with increase in the power-law exponents $k$. With increase in the $k$, the plate gets to fully Steel. The Young's modulus of Steel is bigger than Zirconia's. As it is expected, with increase the $k$, the Young's modulus and bending rigidity of the plate increase according to equation (1). So, the strength of material increases and the critical buckling loads increases naturally. 


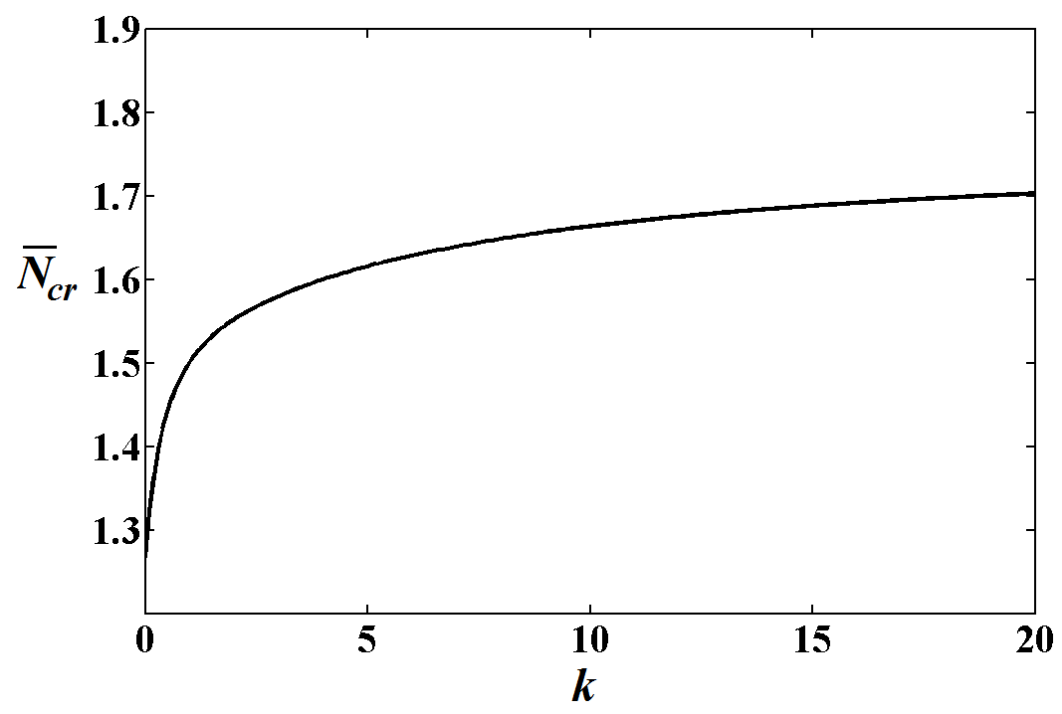

Fig. 2. The effect of the material distribution parameter $k$ on the dimensionless critical buckling loads $\bar{N}_{\text {cr }}$.

Figure 3 displays the relationship between of porosity parameter $a$ and the dimensionless critical buckling loads of the non-homogeneous porous plate for different the material distribution parameters. It is seen from figure 3 that the dimensionless critical buckling loads decrease with increase with increase porosity parameter $a$. This is because, with increase in the porosity, the strength of the material decreases. So, the critical buckling loads decreases naturally. It shows that Porosity parameters play an important role on the stability of the non-homogeneous porous plates.

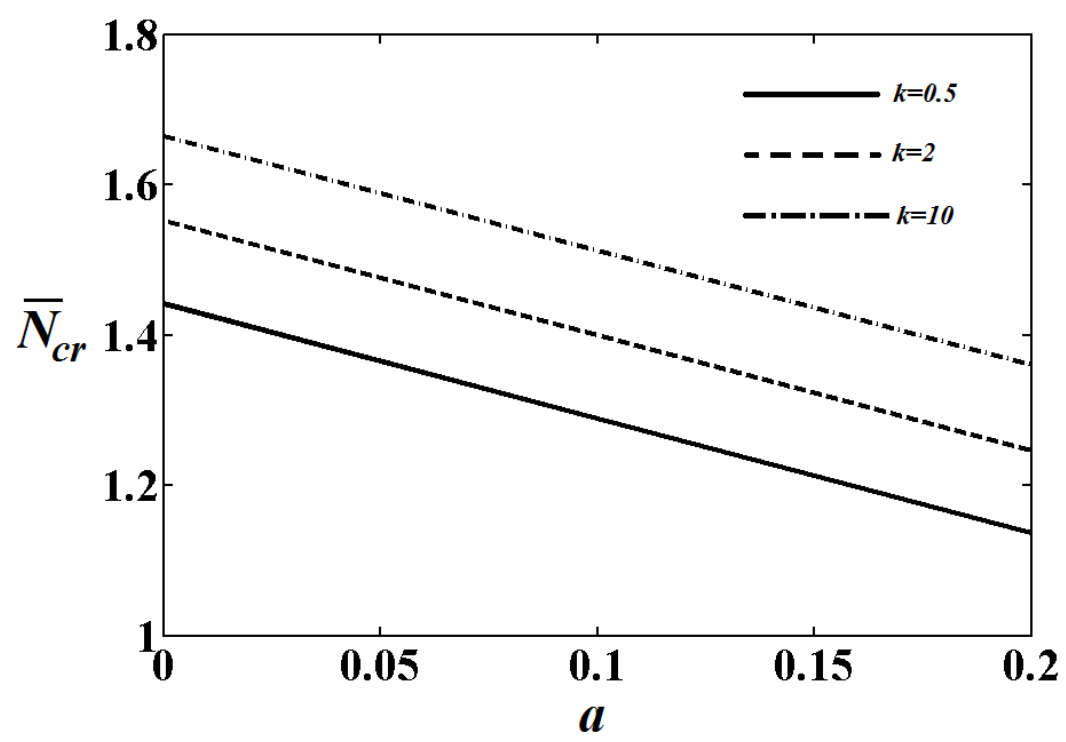

Fig. 3. The effect of the porosity parameter $a$ on the dimensionless critical buckling loads $\bar{N}_{\text {cr }}$ for different the material distribution parameters. 


\section{Conclusions}

In this paper, stability analysis of a simply supported porous non-homogeneous plate is studied by using Generalized Differential Quadrature Method. Material properties of the plate depend on both position and porosity. The Classical plate theory is used in the kinematic model of the plate. The effects of the porosity and material distribution parameters on the critical buckling loads of the nonhomogeneous plate are presented in figures. Numerical results show that the porosity has important role on the stability of the non-homogeneous plate.

\section{References}

[1] Reddy, J.N., and Chin, C.D., Thermomechanical analysis of functionally graded cylinders and plates, Journal of Thermal Stresses, 21, 6,.593-626, 1998.

[2] Reddy, J.N., Analysis of functionally graded plates, International Journal for Numerical Methods in Engineering, 47, 1-3, 663-684, 2000.

[3] Yanga, J. and Shen, H.S., Non-linear analysis of functionally graded plates under transverse and in-plane loads, International Journal of Non-Linear Mechanics, 38, 4, 467-482,2003.

[4] Lanhe, Wu., Thermal buckling of a simply supported moderately thick rectangular FGM plate, Composite Structures, 64, 2, 211-218,2004.

[5] Abrate, S., Free vibration, buckling, and static deflections of functionally graded plates, Composites Science and Technology, 66, 14, 2383-2394,2006.

[6] Chi, S.H. and Chung, Y.L., Mechanical behavior of functionally graded material plates under transverse load-Part I: Analysis, International Journal of Solids and Structures, 43, 13, 36573674, 2006.

[7] Samsam Shariat, B.A. and Eslami M.R., Buckling of thick functionally graded plates under mechanical and thermal loads, Composite Structures, 78, 3, 433-439,2007.

[8] Zhao, X., Lee, Y.Y. and Liew, K.M., Mechanical and thermal buckling analysis of functionally graded plates, Composite Structures, 90, 2, 161-171,2009.

[9] Akbaş, Ş.D., Static analysis of a functionally graded beam with edge cracks on elastic foundation, Proceedings of the 9 th International Fracture Conference, Istanbul, Turkey, 2011.

[10] Zhao, X., Lee, Y. Y. and Liew, K. M., Free vibration analysis of functionally graded plates using the element-free $k p$-Ritz method, Journal of sound and Vibration, 319, 3, 918-939,2009.

[11] Mohammadi, M., Saidi, A.R. and Jomehzadeh, E., Levy solution for buckling analysis of functionally graded rectangular plates, Applied Composite Materials, 17, 2, 81-93,2010.

[12] Fereidoon, A., Asghardokht Seyedmahalle, M. and Mohyeddin, A., Bending analysis of thin functionally graded plates using generalized differential quadrature method, Archive of Applied Mechanics, 81, 11, 1523-1539,2011.

[13] Akbaş, Ş.D. and Kocatürk, T., Post-buckling analysis of a simply supported beam under uniform thermal loading, Scientific Research and Essays, 6,5, 1135-1142, 2011.

[14] Civalek, Ö., Korkmaz, A. and Demir,C., Discrete singular convolution approach for buckling analysis of rectangular Kirchhoff plates subjected to compressive loads on two-opposite edges, Advances in Engineering Software, 41, 4, 557-560, 2010.

[15] Kocatürk, T. and Akbas, Ş.D., Post-buckling analysis of Timoshenko beams with various boundary conditions under non-uniform thermal loading, Structural Engineering and Mechanics, 40,3, 347-371, 2011.

[16] Kocatürk, T., Eskin ,A. and Akbaş Ş.D. Wave propagation in a piecewise homegenous cantilever beam under impact force, International Journal of Physical Sciences, 6, 16, 3867-3874, 2011. 
[17] Kumar, J.S., Reddy, B.S., Reddy, C.E. and Reddy, K.V.K., Higher order theory for free vibration analysis of functionally graded material plates, ARPN J Eng Appl Sci, 6, 10, 105-111,2011.

[18] Jadhav, P.A. and Bajoria, K.M., Buckling of piezoelectric functionally graded plate subjected to electro-mechanical loading, Smart Materials and Structures, 21,.10, 105005,2012.

[19] Akbaş, Ş.D. Free vibration characteristics of edge cracked functionally graded beams by using finite element method. International Journal of Engineering Trends and Technology, 4(10), 4590-4597,2013.

[20] Singh, J. and Shukla, K.K., Nonlinear flexural analysis of functionally graded plates under different loadings using RBF based meshless method, Engineering Analysis with Boundary Elements, 36, 12, 1819-1827,2012.

[21] Kocatürk and Akbas, Ş.D., Thermal post-buckling analysis of functionally graded beams with temperature-dependent physical properties. Steel and Composite Structures, 15, 5, 481-505, 2013.

[22] Daouadji, T.H., Tounsi and Adda Bedia, E-A., Analytical solution for bending analysis of functionally graded plates, Scientia Iranica, 20, 3, 516-523, 2013.

[23] Akbaş, Ş.D.. Geometrically nonlinear static analysis of edge cracked Timoshenko beams composed of functionally graded material, Mathematical Problems in Engineering, 2013, 2013.

[24] Asemi, K. and Shariyat, M., Highly accurate nonlinear three-dimensional finite element elasticity approach for biaxial buckling of rectangular anisotropic FGM plates with general orthotropy directions, Composite Structures, 106, 235-249,2013.

[25] Akbaş, Ş. D. and Kocatürk, T., Post-buckling analysis of functionally graded three-dimensional beams under the influence of temperature. Journal of Thermal Stresses, 36, 12, 1233-1254, 2013.

[26] Czechowski, L. and Kowal-Michalska, K., Static and dynamic buckling of rectangular functionally graded plates subjected to thermal loading, Strength of Materials, 45, 6, 666$673,2013$.

[27] Kocatürk, T. and Akbas, Ş.D., Post-buckling analysis of Timoshenko beams made of functionally graded material under thermal loading, Structural Engineering and Mechanics, 41,6, 775-789, 2012.

[28] Tahouneh, V., Free vibration analysis of thick CGFR annular sector plates resting on elastic foundations, Structural Engineering and Mechanics, 50, 6, 773-796, 2013.

[29] Akbaş, Ş.D., Free vibration of axially functionally graded beams in thermal environment, International Journal of Engineering and Applied Sciences, 6(3), 37-51, 2014.

[30] Swaminathan, K., and Naveenkumar, D.T., Assessment of First Order Computational Model for Free Vibration Analysis of FGM Plates, International Journal of Scientific and Engineering Research, 4, 5, 115-118, 2013.

[31] Van Long, N., Quoc, T.H. and Tu, T.M., "Bending and free vibration analysis of functionally graded plates using new eight-unknown shear deformation theory by finite-element method", International Journal of Advanced Structural Engineering, vol. 8., No.4, pp.391-399, 2016.

[32] Akbaş, Ş.D., Free vibration and bending of functionally graded beams resting on elastic foundation, Research on Engineering Structures and Materials, 1,1, 2015.

[33] Akbaş, Ş.D. On Post-Buckling Behavior of Edge Cracked Functionally Graded Beams Under Axial Loads. International Journal of Structural Stability and Dynamics, 15, 4, 1450065, 2015

[34] Akbaş, Ş.D., Post-buckling analysis of axially functionally graded three-dimensional beams. International Journal of Applied Mechanics, 7, 3, 1550047, 2015.

[35] Civalek, Ö., Free vibration of carbon nanotubes reinforced (CNTR) and functionally graded shells and plates based on FSDT via discrete singular convolution method, Composites Part B: Engineering, 111, 45-59, 2017. 
[36] Civalek, Ö. (2017). Buckling analysis of composite panels and shells with different material properties by discrete singular convolution (DSC) method. Composite Structures, 161, 93-110, 2017.

[37] Mercan, K., Ersoy, H. and Civalek, Ö., Free vibration of annular plates by discrete singular convolution and differential quadrature methods. Journal of Applied and Computational Mechanics, 2,3, 128-133, 2016.

[38] Akbaş, Ş.D., Free vibration of edge cracked functionally graded microscale beams based on the modified couple stress theory, International Journal of Structural Stability and Dynamics, $1750033,2016$.

[39] Barati, M.R. and Zenkour, A.M., Electro-thermoelastic vibration of plates made of porous fuctionally graded piezoelectric materials under various boundary conditions, Journal of Vibration and Control, doi: 10.1177/1077546316672788, 2016.

[40] Akbaş, Ş.D. (2016). Static Analysis of a Nano Plate by Using Generalized Differential Quadrature Method, International Journal of Engineering and Applied Sciences, 8, 2, 30-39, 2016.

[41] Mercan,K., Demir, Ç. And Civalek, Ö., Vibration analysis of FG cylindrical shells with powerlaw index using discrete singular convolution technique, Curved and Layered Structures, 3, 1, 2016.

[42] Akbaş, Ş.D. (2016). Wave propagation in edge cracked functionally graded beams under impact force, Journal of Vibration and Control, 22, 10, 2443-2457,2016.

[43] Wattanasakulpong, N. and Ungbhakorn, V.,Linear and nonlinear vibration analysis of elastically restrained ends FGM beams with porosities, Aerospace Science and Technology, 32, 1, 111-120, 2014.

[44] Mechab, I., Mechab, B., Benaissa, S., Serier, B., Bouiadjra, B.B., Free vibration analysis of FGM nanoplate with porosities resting on Winkler Pasternak elastic foundations based on two-variable refined plate theories, Journal of the Brazilian Society of Mechanical Sciences and Engineering, 38, 8, 2193-2211, 2016.

[45] Mechab, B., Mechab, I., Benaissa, S., Ameri, M. and Serier, B., Probabilistic analysis of effect of the porosities in functionally graded material nanoplate resting on Winkler-Pasternak elastic foundations, Applied Mathematical Modelling, 40, 2, 738-749, 2016.

[46] Şimşek, M. and Aydın, M., Size-dependent forced vibration of an imperfect functionally graded (FG) microplate with porosities subjected to a moving load using the modified couple stress theory, Composite Structures, 160, 408-421, 2017.

[47] Al Jahwari, F. and Naguib, H.E., Analysis and homogenization of functionally graded viscoelastic porous structures with a higher order plate theory and statistical based model of cellular distribution, Applied Mathematical Modelling, 40, 3, 2190-2205, 2016.

[48] Ebrahimi,F. and Jafari, A., A Higher-Order Thermomechanical Vibration Analysis of Temperature-Dependent FGM Beams with Porosities, Journal of Engineering, doi:10.1155/2016/9561504, 2016.

[49] Ebrahimi, F., Ghasemi, F. and Salari, E., Investigating thermal effects on vibration behavior of temperature-dependent compositionally graded Euler beams with porosities, Meccanica, 51, 1, 223-249, 2016.

[50] Chen, D., Yang, J. and Kitipornchai, S., Nonlinear vibration and postbuckling of functionally graded graphene reinforced porous nanocomposite beams, Composites Science and Technology, 142, 235-245, 2017.

[51] Kitipornchai, S., Chen, D. and Yang, J., Free vibration and elastic buckling of functionally graded porous beams reinforced by graphene platelets, Materials\&Design, 116, 656-665, 2017.

[52] Akbaş, Ş.D., Vibration and Static Analysis of Functionally Graded Porous Plates, Doi: 10.22055/jacm.2017.21540.1107, Journal of Applied and Computational Mechanics, 2017. 
[53] Shu, C. and Du, H., Implementation of clamped and simply supported boundary conditions in the GDQ free vibration analysis of beams and plates, Int. J. Solids Struct. 34, 819-835, 1997.

[54] Shu, C., Differential Quadrature and its Application in Engineering, Springer, 2000.

[55] Chen, C.N., Discrete element analysis methods of generic differential quadrature, Lecture Notes in Applied and Computational Mechanics, vol. 25, Springer, 2006.

[56] Quan, J.R. and Chang, C.T. New insights in solving distributed system equations by the quadrature methods, Comput. Chem. Eng. 13, 779-788, 1989. 